\title{
O recorrente apelo das reformas gerenciais: uma breve comparação
}

Revista do

Serviço

Público

Ano 54

Número 4

Out-Dez 2003

\author{
Francisco Gaetani
}

\section{Introdução}

Duas significativas iniciativas reformistas distintas e desvinculadas uma da outra ocorreram no decorrer dos dois mandatos do governo do presidente Fernando Henrique Cardoso (FHC): a reforma do aparelho de Estado liderada por Bresser Pereira e o Plano Plurianual (PPA)20002003 comandado por José Silveira. Ambas iniciativas reivindicavam o logo gerencial para suas iniciativas, embora com matizes distintas. Este texto é um esforço de comparação entre os dois processos de reformas, com a finalidade de contribuir para a compreensão de ambos e para a identificação de possíveis lições para o momento atual.

A retórica gerencial constitui fonte de permanente apelo junto a governantes e dirigentes que, ao se depararem com problemas que se lhes parecem inéditos, buscam nas teorias e doutrinas de administração, oriundas do setor privado, subsídios para suas formulações e decisões.

Este não é um fenômeno novo, nem no mundo nem no Brasil. As ligações da chamada administração científica com o movimento conhecido nos Estados Unidos como "progressive public administration" datam de, pelo menos, um século. Nas origens da reforma administrativa de 1967, a preocupação com a incorporação de técnicas de gestão em uso por governos e multinacionais fazia parte da proposta que veio a ser encampada pelo regime autoritário que se instalava.

Curiosamente, no caso brasileiro as duas experiências em questão tiveram fontes de inspiração bastante distintas. Enquanto Bresser Pereira foi buscar subsídios junto à chamada Nova Gestão Pública, Silveira trouxe das práticas do setor privado muitas das idéias que embasaram o plano

\section{Francisco \\ Gaetani é mestre em administração pública e políticas públicas pela London School of Economics and Political Science, \\ Especialista em Políticas \\ Públicas e \\ Gestão \\ Governamental, professor da PUC-MG e atualmente Assessor do Representante Residente do Programa das Nações Unidas para o \\ Desenvolvimento no Brasil. \\ Contato: francisco.gaetani @undp.org.br}


plurianual que veio a ser conhecido como Avança Brasil. Mais intrigante ainda é o fato de as duas iniciativas - verificadas sob o mesmo Presidente da República e o mesmo Ministro da Fazenda - apresentarem poucas sobreposições, e a segunda ter-se iniciado praticamente sem vinculação com a primeira, em que pese o locus institucional de uma ser contíguo ao da outra.

As principais referências teóricas utilizadas nestas comparações são extraídas do modelo desenvolvido por Kingdon (1995), para analisar os processos de formação de agenda, especificação de políticas e tomada de decisão em políticas públicas. Trata-se de destrinchar os elementos configuradores do policy-making process exclusive à dinâmica de implementação que se segue à tomada de decisão nas políticas de gestão pública em questão.

Cabe, ainda, registrar que os elementos de políticas de gestão pública focalizados neste trabalho são basicamente: a organização das instituições públicas e o serviço público civil no primeiro mandato e o processo de planejamento no segundo mandato. Houve novidades em relação aos dois primeiros temas também no segundo mandato, assim como caberia uma análise das mudanças no processo de planejamento no primeiro mandato. A preocupação do texto, no entanto, é com o fato de a retórica gerencial ser utilizada, mas apenas nos dois casos em questão.

O texto do trabalho está estruturado em seis partes. A primeira é esta breve introdução. A segunda é um breve comentário sobre outra importante reforma gerencial ocorrida na administração pública brasileira: a reforma administrativa de 1967, que abordou problemas muito semelhantes aos que continuam a desafiar a capacidade do Estado brasileiro. A terceira parte é uma descrição dos principais pontos da reforma do aparelho do Estado empreendida por Bresser Pereira no primeiro mandato de FHC. A quarta parte proporciona uma narrativa semelhante ao processo de gestação do Avança Brasil, o plano plurianual emblemático do segundo mandato de FHC. Na quinta parte são feitas comparações entre ambos, com base em categorias analíticas derivadas de Kingdon (1995) e Hood (1994). Finalmente, a conclusão faz algumas considerações sobre possíveis lições a serem extraídas de ambos episódios à luz do momento do atual governo.

\section{Um precedente importante': a reforma administrativa de 1967}

A reforma administrativa de 1967 - muito citada, mas pouco compreendida - foi precursora de muitas das idéias no Brasil, de muitas das idéias que, quase vinte anos depois, viriam a ser apresentadas como parte 
de uma revolução gerencial. Embora muitos seus principais conceitos

tenham sido obscurecidos pela evolução do regime rumo a um maior endurecimento e fechamento, várias das principais novidades de 1995 já eram mencionadas naquela época.

O ponto de partida da reforma foram os estudos da chamada Comissão Amaral Peixoto - então um ministério extraordinário que teve o próprio à frente no decorrer do turbulento ano de 1963. Liderada por Benedito Silva, homem de confiança de Simões Lopes que presidia a Fundação Getúlio Vargas, a proposta encaminhada ao Congresso continha, na verdade, um detalhado diagnóstico da administração pública brasileira, mas pouco avançava em termos de proposições, apesar do consenso em torno da exaustão, cujas bases haviam sido lançadas na década de 30 a partir do governo democrático de Vargas.

Os principais problemas apontados pelos estudos eram a falta de coordenação das ações do governo combinados com a excessiva centralização da administração federal na presidência da República, permanentemente congestionada pela necessidade da assinatura presidencial em atos dos mais simples aos mais complexos. O fato de as sucessivas tentativas de reforma dos anos $50^{2}$ terem fracassado já sinalizava, no entanto, que não se trataria de assunto de aprovação tranqüila, seja no interior do governo, seja no próprio Congresso.

O fato de Castelo Branco ter participado da coordenação dos estudos da Comissão Amaral Peixoto, no âmbito das Forças Armadas, fez que ele tivesse uma aguda percepção da urgência do problema e o remeteu ao topo de sua agenda, mas logo ficou claro para o novo governo que a proposta do Congresso era extremamente tímida, tendo em vista dois fatores: as ambições transformadoras do novo regime e as condições políticas propiciadas pelo recém-empossado governo revolucionário. Com a anuência dos relatores da proposta no Congresso - Gustavo Capanema e o próprio Amaral Peixoto -, o governo retirou a proposta do Congresso e optou por dar tratamento de altíssimo nível ao assunto através da criação de uma comissão - Comissão de Estudos Técnicos para a Reforma Administrativa (Comestra) - encarregada de propor novo desenho para a administração pública brasileira.

Roberto Campos foi designado para secretariar - função transferida para seu auxiliar José Nazareth Teixeira Dias - a comissão presidida, que seria por Hélio Beltrão, e que contaria ainda com membros como Simões Lopes, Carlos Veloso, Jorge Flores e outros grandes nomes da época, além de quatro representantes das Forças Armadas. Foram reunidos à disposição do projeto o que havia de melhor na inteligência nacional a respeito do assunto, embora cada membro fosse portador de uma visão distinta sobre o tema. ${ }^{3}$ 
O embate de idéias e projetos na Comestra foi surpreendentemente duro. A primeira baixa foi Simões Lopes, cuja visão, mais próxima do projeto definido como obsoleto no Congresso, defendia o fortalecimento do Departamento de Administração e Serviço Público (Dasp), bem como sua transformação no órgão líder do processo de reforma. $\mathrm{O}$ confronto maior, no entanto, deu-se entre duas visões de corte gerencial entre Hélio Beltrão e Teixeira Dias. Ao final de quase um ano de trabalhos, a comissão se dissolveu em meio a um impasse constrangedor dado o peso político de Hélio Beltrão e as vinculações de Teixeira Dias com Roberto Campos.

Beltrão defendia, já desde aquela época, os princípios de descentralização, delegação e desburocratização que o tornariam famoso, quase quinze anos mais tarde quando assumiu o Ministério Extraordinário da Desburocratização no governo Figueiredo. Enfatizava os princípios do movimento conhecido no âmbito internacional atualmente como "liberation management", que pressupõe alta delegação de responsabilidades para os gerentes que deveriam ser dispensados de uma série de controles burocráticos ex-ante e cobrados a partir de resultados. Combinava esta visão com sua crítica aos formalismos típicos da burocracia brasileira que deveriam ser objeto de permanentes esforços de simplificação radical, idéias estas que viriam pôr em prática mais tarde, quando ministro da Desburocratização.

Teixeira Dias era um quadro com visão da complexidade da máquina pública, só comparável com a seu superior hierárquico Roberto Campos. Conhecia a fundo o serviço público norte-americano, inglês e francês. Mais importante, no entanto, tinha visão da articulação entre os processos de planejamento e administração pública bastante avançada para a época ${ }^{4}$, porque defendia articulação maior entre os processos de programação orçamentária e financeira com formas diferenciadas de organização das instituições públicas e, naturalmente, do serviço público. Teixeira Dias estava, até então, na Light, onde se familiarizara com as técnicas de Planning, Programming, and Budgeting Systems (PPBS), em voga tanto no governo norte-americano quanto nas empresas multinacionais. Neste sentido era capaz de traduzir, para a Administração Federal, muitas das idéias que Roberto Campos tinha para a institucionalização do planejamento no Brasil.

O impasse entre ambos não é de fácil compreensão, tendo em vista a aparente complementaridade de idéias existentes e o fato de terem juntos trabalhado no desenho e na implementação da Petrobras. Ambos eram inovadores, esposavam idéias com forte componentes gerenciais, e rejeitavam a visão centralista esposada por Simões Lopes. Porém, havia dois elementos que os situavam em campos opostos: política e personalidade ${ }^{5}$. 
No plano político, Beltrão - um comunicador nato liberal com perfil de político apaixonado pelo debate público - foi progressivamente se posicionando como oponente a Roberto Campos - caracterizado como o tecnocrata frio e autoritário, propenso a abusar dos excepcionais atributos de legislativos do primeiro governo revolucionário. Teixeira Dias era quase uma extensão de Roberto Campos para assuntos relacionados com a reforma administrativa. No plano pessoal, Teixeira Dias era um detalhista, preocupado com a instrumentalização do Estado e com a institucionalização de uma legislação que traduzisse sua visão e a de Roberto Campos da administração pública. Beltrão defendia legislações simples contendo basicamente princípios e orientações gerais e opunha-se radicalmente a detalhamentos típicos da tradição jurídica brasileira detalhista.

No final de 1965 e após o desfecho da crise político-institucional que produziu o AI-2, Castelo Branco e Roberto Campos voltam sua atenção para o assunto e delegam a Teixeira Dias o detalhamento final da proposta que resultaria nos Decretos-leis no 199 e no 200, na véspera da passagem do poder para Costa e Silva. Teixeira Dias incorporou todas as idéias de Beltrão - em especial os princípios de descentralização e delegação - no início do texto legal, porém detalhou no seu corpo todas as idéias que defendia, visando assegurar a modernização da administração pública brasileira. Entre estas idéias destacam-se entre outras: a) a articulação entre a planejamento, orçamento e execução financeira; b) a criação de mecanismos de controle interno ao Executivo e a transformação do controle externo em ex-post ao invés de ex-ante; c) a tipificação das formas organizacionais da administração pública direta e indireta; d) o fortalecimento do serviço público civil através de sua profissionalização via sistema de carreiras, e e) a criação de um órgão - de status ministerial ou não destinado a implementar a reforma administrativa.

Ironicamente, Helio Beltrão é convidado para assumir o Ministério do Planejamento por Costa e Silva em 1967 e torna-se o representante dos liberais em um governo ainda mais "duro" que o anterior. $\mathrm{O}$ acúmulo das funções de planejamento e administração não o intimida, tendo em vista sua trajetória pessoal e sua imensa capacidade de mobilização e articulação. A evolução política da conjuntura leva à radicalização política do regime e à asfixia de suas possibilidades de intervenção. Em conseqüência, a área de administração é eclipsada imediatamente após seu afastamento do governo no final de 1969, em que pese ter sido convidado a permanecer no governo Médici. Paralelamente, a área de planejamento é definitivamente consolidada com a ascensão de seu adjunto Reis Veloso à frente do Ministério, onde permanece por quase uma década. 
As idéias de Cardoso sobre a reforma do Estado quando assumiu a Presidência da República datavam de sua atuação na Constituinte e na fracassada Revisão Constitucional. Cardoso não considerava que fossem necessárias grandes reformas transformadoras da administração pública, mas sim ajustes que dessem condições para a liberação das forças produtivas do mercado. As reformas deveriam ser localizadas e cirúrgicas como, por exemplo, o fim do monopólio público - de modo a melhorar o funcionamento do mercado. Na esfera do Executivo, não acreditava que mudanças pudessem vir a fazer grandes diferenças, tendendo a preferir mecanismos como os adotados no período JK e desenvolvimentista do regime autoritário que favoreciam mecanismos de administração paralela via ação direcionadas de grupos ad hoc e/ou empresas estatais.

O convite a Bresser Pereira, velho companheiro de Cardoso de idéias e militância política - além do coordenador financeiro da campanha presidencial -, para integrar o Ministério que viria a tomar posse em janeiro de 1995, abriu novas possibilidades na agenda nacional para a problemática das políticas de gestão pública. Bresser Pereira, Clovis Carvalho e Cardoso concordaram em elevar o status da então secretaria da presidência - Secretaria de Administração Federal - para Ministério da Administração e da Reforma do Estado (MARE). Nessa mudança, Bresser trocou o acesso institucional e físico ao presidente - que tinha em função de suas relações pessoais - por uma plataforma institucional de maior robustez, que trazia no nome um mandato: a reestruturação da administração pública federal.

Em poucas semanas, Bresser já tinha uma estratégia distinta da que norteou o encaminhamento de outras reformas em discussão no período: propor uma emenda constitucional para tratar de forma propositiva do tema da administração pública, ao contrário, por exemplo, da reforma previdenciária que buscavam "desconstitucionalizar" uma série de pontos remetendo-os ao plano infraconstitucional - o que viria a enfrentar grandes resistências no Congresso relutante em fornecer um "cheque em branco" ao Executivo $^{6}$ (Melo, 2002). Ao dar um tratamento de reforma constitucional ao assunto de sua pasta, Bresser Pereira assegurou que o tema da reforma do Estado, isto é, da reforma do aparato do Estado como viria a detalhar pouco tempo depois, ocuparia uma posição de destaque na agenda do Executivo.

Após quatro meses de governo, Bresser Pereira e sua equipe em grande medida constituída por colegas e ex-alunos(as) da Fundação Getúlio Vargas de São Paulo sobre os quais o ministro possuía notável ascendência - já tinha não apenas estruturado o novo ministério como 
também um primeiro desenho da proposta de reformulação da estrutura do Estado brasileiro para apresentar ao Presidente (MARE, 1995 e 1997).

A Câmara da Reforma do Estado, criada para funcionar como instância de discussão das propostas de apresentadas pelo MARE, passou então a se constituir na arena de aprimoramento das idéias defendidas por Bresser Pereira e sua equipe. Delinearam-se, então, três tipos de oposição a Bresser Pereira: duas explícitas e uma silenciosa.

A primeira era comandada pelo secretário-geral da Presidência Eduardo Jorge, doutor em Administração Pública e assessor de Cardoso desde os tempos da Assembléia Nacional Constituinte - que demonstrava grande ceticismo em relação às possibilidades de sucesso de reformas compreensivas da administração pública brasileira. Eduardo Jorge tendia a considerar que o governo dispunha dos meios de operar as mudanças que desejava sem necessariamente recorrer a alternações no texto constitucional.

A segunda fonte de oposição partia do ministro-chefe da Casa Civil que não demonstrava bastante ceticismo em relação a mudanças que privilegiavam estruturas organizacionais e legislações de pessoal. Oriundo do setor privado e já tendo trabalhado com Bresser Pereira anteriormente no Governo Montoro, Carvalho desconfiava do voluntarismo ativista de seu colega de Ministério que, em função das funções que desempenhava, disputava geralmente com sucesso alguns espaços em que as competências de ambos ministros se sobrepunham ${ }^{7}$.

A terceira fonte de oposição era invisível e partia da área econômica. Tratava-se de uma desconfiança em relação ao papel do ex-ministro da Fazenda Bresser Pereira na crítica à política macroeconômica conduzida pelo Ministro da Fazenda e pelo Banco Central. Pela proximidade do Presidente e por ter, sob sua jurisdição, assuntos com impactos sobre as finanças públicas, Bresser não teve o apoio efetivo necessário em muitas das inovações que propunha, em que pese ter procurado alinhar a ação de seu ministério e o conteúdo de suas propostas às prioridades da área macroeconômica.

Apesar das oposições que enfrentou no seio do governo, Bresser Pereira foi capaz de convencer o Presidente a encaminhar a proposta de Emenda Constitucional ao Congresso ainda no segundo semestre do primeiro ano do mandato de Cardoso, ao mesmo tempo em que sua equipe saía pelo País discutindo o livro branco Plano Diretor da Reforma do Aparato do Estado Brasileiro (MARE, 1995). O trabalho político realizado junto aos governadores - imobilizados pelos gastos excessivos com pessoal acima da Lei Camata - foi decisivo para a aquiescência de Cardoso que, no entanto, chamou a atenção de Bresser para a necessidade de convencer o próprio Executivo dos méritos de sua proposta (guardando, assim, distância da proposta de seu próprio ministro). 
O conteúdo da proposta de reforma apresentada era predominantemente gerencialista, embora reservasse um lugar de destaque para a formação do chamado núcleo estratégico do Estado, locus designado para a implementação e consolidação das chamadas reformas meritocráticas perseguidas desde a década de 30 . Se o desenho da proposta buscava uma articulação entre novos e velhos desafios da administração pública brasileira - Bresser Pereira descartava abordagens seqüenciais do problema das reformas -, a retórica e as ênfases no debate público eram quase que exclusivamente gerenciais (Gaetani, 1998).

A imagem-objetivo buscada por Bresser Pereira era a da flexibilização da administração pública, no caso de suas estruturas organizacionais e dos regimes de contratação de pessoal. A flexibilização era apresentada como requisito para múltiplos objetivos como a busca da eficiência, a viabilização de processos de delegação e descentralização, a implementação do orçamento global em organizações públicas autônomas via contratos de gestão, a valorização de mecanismos diferenciados de reconhecimento do mérito, a contratualização de resultados e outros.

Três vetores simultâneos conviveram no decorrer do período 1995 1998: os princípios típicos da progressive public administration expressos principalmente na política de concursos seletivos para as carreiras que viriam a integrar mais tarde as carreiras do ciclo de gestão e as duas vertentes contraditórias integrantes da Nova Gestão Pública, o gerencialismo e a escola da escolha pública (Aucoin, 1990). O gerencialismo - representado principalmente pelo Ministro e pela Secretaria da Reforma do Estado - valorizava a autonomia das novas formas de organização pública, mecanismos de delegação e descentralização e a capacidade inovadoras e empreendedoras dos dirigentes governamentais. Da escolha da escola pública emanavam os vetores de desconfiança em relação ao corporativismo burocrático e de necessidade de intensificar os controles sobre a burocracia, presentes em especial no âmbito da Secretaria Executiva do MARE e da Presidência da ENAP Escola Nacional de Administração Pública.

Quase três anos após seu envio para o Congresso, a Emenda Constitucional, bastante diluída e suavizada, foi finalmente aprovada em pleno ano eleitoral. Mesmo assim algumas decisões importantes como a quebra do Regime Jurídico Único foram aprovadas. Ao longo deste período muitos dos conteúdos da proposta foram implementados na medida em que se percebia que não necessitavam da aprovação constitucional para tal caso da criação das Organizações Sociais e Agências Executivas. Paralelamente, foi feito um esforço massivo de disseminação das idéias da Nova Gestão Pública, notadamente pela ENAP, junto ao governo federal.

As propostas do MARE, no entanto, não conseguiram o apoio de ministros estratégicos da presidência - como o ministro da Casa Civil e o 
secretário-geral da Presidência -, da área econômica - como os da

Fazenda e Planejamento - e de outros ministérios-chave - como os da Educação e da Saúde (este, exceto, em breve intervalo) - para o sucesso dos esforços reformistas. Muitos avanços ocorreram, mas no âmbito do próprio MARE, como o controle da folha de pagamento e a retomada de concursos para carreiras estratégicas de analistas de planejamento e orçamento, analistas de finanças e controle e gestores governamentais.

Ao final do primeiro mandato de Cardoso, Bresser Pereira passou a apoiar a idéia da unificação do MARE e do Ministério de Planejamento, de modo a manter sob comando único os instrumentos e recursos necessários para a implementação da reforma. A transição do primeiro para o segundo mandato coincidiu com a reestruturação do governo em meio às turbulências causadas pela crise financeira internacional e por denúncias de corrupção que atingiram auxiliares de Cardoso que se afastaram, então, do governo.

\section{As inovações gerenciais do Brasil em Ação e do Avança Brasil}

A substituição de José Serra por Antonio Kandir na Pasta do Planejamento em função de divergências com o Ministério da Fazenda deu uma nova dimensão ao esforço de revitalização do processo de planejamento, abandonado desde o final dos anos setenta. Kandir trouxe para comandar a Secretaria de Planejamento e Investimentos José Silveira, seu ex-companheiro do Governo Collor, então envolvido com a implementação do Programa Brasileiro da Qualidade e Produtividade.

No decorrer da implementação do plano plurianual 1996-1999, foi ficando evidente para os dirigentes na frente do processo, a necessidade de insular um conjunto de projetos estratégicos para o governo que deveriam ser objeto de tratamento diferenciado por parte do governo. A idéia era agrupar um conjunto de iniciativas e identificá-las, sendo de interesse direto do presidente (Kandir, 1995).

Estes projetos passaram a fazer parte de um pacote de investimentos estratégicos chamado Brasil em Ação, orientados para a superação de gargalos de infra-estrutura e redução do chamado custo Brasil. Estes investimentos passaram a receber tratamento de projetos, gerenciados enquanto tal e com gerente especificamente designado como responsável por sua execução. A ênfase na responsabilização individualizada pelos resultados em projetos de grande porte foi importante novidade da experiência.

José Silveira era um engenheiro egresso da Petrobras, com sólida formação nas áreas de qualidade e gerência de projetos, duas policy 
communities estruturadas, socialmente reconhecidas e com profundas raízes no setor privado. Com apoio do ministro-chefe da Casa Civil Clovis Carvalho, Kandir e Silveira começaram a amadurecer a idéia de levar ao Presidente um plano para o segundo mandato, mesmo em uma conjuntura que se delineava contracionista.

Para operar substantiva modificação no processo de elaboração de planos plurianuais e, em especial, realocação substantiva de recursos, era necessário romper com o incrementalismo inercial do processo orçamentário. Tratava-se, então, de recuperar a centralidade da categoria programa no processo de elaboração orçamentária, obscurecida por práticas classificatórias que se tornaram rígidas com o passar do tempo.

Silveira, como Bresser, ressaltava a necessidade de uma revolução gerencial, mas contrariamente a Bresser não se ocupava com formas de organização das instituições públicas, nem tampouco com os problemas do regime de pessoal destas organizações. O foco de suas preocupações eram os processos de trabalho, processos estes que se beneficiaram enormemente dos desenvolvimentos tecnológicos de sistemas de trabalho que traduziam, de forma estruturada, os princípios de contratualização de resultados que se buscava institucionalizar.

A transição de 1998 para 1999 teve outra dinâmica para os setores comprometidos com as reformas gerenciais que seriam introduzidas no processo de elaboração do PPA 2000-2003, mais tarde batizado como Avança Brasil. O eclipse de Bresser Pereira - cujos esforços correram em paralelo, mas não de forma convergente com os do Ministério de Planejamento - e a iminência da crise cambial produziram uma janela de oportunidade rapidamente aproveitada por Kandir, Silveira e sua equipe, em que pese a mudança de dirigentes em curso no período.

Em meados de 1998, foram contratadas análises com a finalidade de subsidiar a estruturação de uma programação de investimento que balizasse inversões públicas e privadas, a partir de sinalizações referenciadas no espaço georeferenciado nacional. O chamado Estudos dos Eixos serviria para subsidiar todo o esforço de revitalização e reprogramação do processo de planejamento nacional com especial atenção para projetos e programas de infra-estrutura física, posteriormente acrescidos de iniciativas na área social e ambiental.

Em dezembro de 1998, foi aprovada uma modificação na legislação orçamentária que permitiria que, na elaboração do PPA 2000-2003, fossem redefinidas prioridades orçamentárias históricas, mas que já não faziam, guardavam relação com as novas ações programáticas que se buscava estabelecer. Assim foram gerados graus de liberdade importantes, para que no segundo mandato de Cardoso fosse possível acomodar novas prioridades. 
Os meses de dezembro, janeiro e fevereiro foram totalmente absorvidos pela administração da crise cambial - responsável pela substituição de dois Presidentes do Banco Central em um período de quinze dias. Em março, com o segundo mandato duramente comprometido pela desvalorização cambial de que Cardoso dispunha para iniciar seu segundo período na Presidência. Da expectativa de elaboração de um plano plurianual vertebrado e ambicioso centrado agora em programas (e não mais em projetos), dotado de um significativo conjunto de novidades e de um discurso articulado, capaz de transmitir à população a mensagem de que o governo tinha um projeto, apesar dos danos produzidos pelas mudanças na política cambial e fiscal.

O Brasil em Ação não chegara a ser objeto de uma avaliação sistemática. Mas foi considerado suficientemente exitoso para justificar sua generalização para todo o plano plurianual seguinte. Passou de 42 projetos no âmbito do Brasil em Ação para 345 programas no Avança Brasil. A figura dos gerentes foi reproduzida na escala massiva com o novo PPA, agora acoplado, também, a um sistema de indicadores de desempenho que traduzia a retórica de contratualização de resultados em um desafio concreto para o Executivo federal.

Paralelamente a este esforço, a carreira de analistas de planejamento e orçamento foi periodicamente sendo alimentada pelos quadros dos concursos públicos realizados no decorrer do processo. Tanto a Secretaria de Planejamento e Investimentos Estratégicos (SPI) quanto a Secretaria de Orçamento e Finanças (SOF) tiveram condições de operar de forma sistêmica, no Ministério de Planejamento (depois Ministério de Planejamento, Orçamento e Gestão) e nas Secretarias de Planejamento, Orçamento e Administração (SPOAs) dos Ministérios Finalísticos.

No âmbito da capacitação de recursos humanos, a Escola Nacional de Administração Pública passou a investir maciçamente no processo de capacitação de dirigentes, gerentes e chefias intermediárias na disseminação dos conteúdos relacionados com o novo PPA. Além deste programa intenso de educação continuada centrada no Avança Brasil, a ENAP cuidava, também, da formação das carreiras de gestores governamentais e analistas de planejamento e orçamento, sempre destacando os principais fundamentos da Nova Gestão Pública.

A implementação do Avança Brasil possibilitou ao governo atravessar o segundo mandato tendo como referência uma programação que, embora sujeita a cortes orçamentários recorrentes devido ao esforço de ajuste fiscal, proporcionava uma imagem objetivo de racionalidade acoplada a uma retórica gerencial aparentemente coerente.

A posição de nodal da SPI e o caráter compulsório da adesão ao processo imposto pelos novos sistemas de informação adotados, consolidados no Sigplan, conferiram ao governo um centro de gravitação 
frágil em função da conjuntura econômica, porém suficientemente estruturado para ser objeto de atenção internacional, dado a surpreendente revitalização da prática de planejamento no Brasil, duas décadas após seu quase abandono pelo governo federal.

Muitos dos elementos do Brasil em Ação e, em especial, do Avança Brasil não possuíam o caráter inovador que advogavam. Já na década de 60, muitas das idéias e técnicas de planejamento e programação orçamentária agrupadas sob a sigla PPBS foram aplicadas - e posteriormente abandonadas - no Brasil, a ponto de servirem de referência para a reforma administrativa de 1967. Mas acopladas à retórica da Nova Gestão Pública, ganharam um novo impulso. Pela primeira vez, desde o governo Castelo Branco, planejamento e gestão voltavam a interagir, de forma potencialmente sinérgica, ainda que muito problemática.

A deliberada opção por ignorar aspectos organizacionais e relacionados a pessoal gerou, no entanto, uma série de dificuldades para o processo de implementação e gestão do PPA. A análise do Banco Mundial (2002) sobre os avanços e as limitações do Avança Brasil aponta, com muita propriedade, os progressos e estrangulamentos ocorridos até a época. A saturação da retórica governamental em relação ao programa não tinha como encobrir as fragilidades e vulnerabilidades do modelo.

A estrutura de incentivos do Avança Brasil não se mostrou nem sustentável nem consistente por não integrar os conteúdos programáticos, informacionais, orçamentários, organizacionais e de recursos humanos. O desenvolvimento de capacidades foi assimétrico, atribuindo-se aos sistemas de informação expectativas que não tinham como atender sem correspondente modificações em outras políticas-chave de gestão pública.

A mudança de governo não produziu retrocessos na sistemática de elaboração do PPA e trouxe apenas um avanço, a publicização e o debate aberto de seus conteúdos nas 27 unidades da Federação sob a liderança da Secretaria-Geral da Presidência. O fato de o novo governo ter mantido a sistemática adotada para a elaboração do PPA, em pleno primeiro ano de uma nova Presidência, sugere que a plataforma existente possui vitalidade e potencialidades de evolução a serem consideradas.

\section{Similaridades e diferenças dos dois enfoques gerenciais}

Os caminhos das reformas, para que entrassem na agenda do Executivo federal em cada ciclo, foram bastante distintos. A entrada de Bresser Pereira no ministério foi decisiva para que o tema reforma do Estado integrasse a pauta de Cardoso no início do governo. No caso do 
Avança Brasil, a trajetória não foi top down, mas bottom up. O tema foi incubado no período anterior. A implementação do Brasil em Ação e o trabalho de preparação da estratégia para a elaboração do Avança Brasil em 1999.

A janela de oportunidade, no caso do primeiro mandato, foi a mudança de governo e a montagem do ministério. O programa de governo (PSDB, 1994) mal tratava do tema reforma do Estado e o fazia de forma convencional sem atribuir-lhe especial importância e muito menos dimensões inovadoras. O conteúdo proposto era o da progressive public administration histórica agenda.

No caso do Avança Brasil, a reeleição de Cardoso, sem dúvida, foi importante, mas dois outros fatores contribuíram para que o PPA 20002003 assumisse o protagonismo que teve no segundo mandato. O primeiro foi o desarme da alternativa desenvolvimentista ensaiada no segundo semestre de 1998 em função de um conjunto de auxiliares de Cardoso afetados pela repercussão na mídia de denúncias relacionadas com o processo de privatização. O segundo foi a crise cambial, que desestruturou a política macroeconômica que vinha sendo implementada. Em março de 1999, o governo não tinha mais nada a propor nem a comemorar, embora tivesse todo um mandato pela frente. O Avança Brasil surge como a principal plataforma para o governo que se reiniciava.

Os atores e os meios utilizados também foram distintos em ambos os casos. No primeiro ciclo, Bresser Pereira comandava uma equipe de quadros por ele recrutados, que dedicaram-se a uma cruzada reformista pelo País. Houve apoio também dos governadores, parte da mídia, setores da burocracia e, em um primeiro momento, do próprio presidente. Os recursos utilizados eram basicamente de autoridade, legais e os meios à disposição do MARE.

O Avança Brasil foi protagonizado por um número maior de atores, uma combinação de burocratas de segundo escalão, ministros de passagem por posições estratégicas e interlocutores do setor privado interessados nas oportunidades de negócio potencialmente decorrentes da proposta. Alguns dos recursos mobilizados foram os mesmos, já outros eram de outra natureza: o apoio de comunidades de especialistas, sistemas de informações gerenciais com impactos sobre todo o Executivo federal e apoios de outras autoridades estrategicamente posicionadas no governo como o da Casa Civil.

Bresser Pereira apoiou-se no Livro Branco sobre a Reforma do Aparato do Estado e no Projeto de Emenda Constitucional para alavancar suas ações. É fato que dispunha de uma série de competências legais para formular propostas e legislar em áreas como pessoal e organizações, mas suas capacidades pervasivas eram limitadas. O Avança Brasil apoiava-se 
na legislação constitucional sobre planos plurianuais, na legislação ordinária sobre orçamentos e nos sistemas de informações estruturantes da execução orçamentária e financeira do governo.

As reformas do primeiro mandato atribuíam grande importância às mudanças legais, estruturas organizacionais e à questão de pessoal. O MARE desenvolveu também um importante conjunto de processos de mudança nas áreas de qualidade e capacitação gerencial. Mas o ciclo de reformas baseado no PPA 2000-2003 focalizava a dinâmica da implementação de programas e os esforços de contratualização de resultados embutidos nos processos de planejamento e execução orçamentário-financeira.

No ciclo de reformas do primeiro mandato, Bresser Pereira praticamente "fundou" uma policy community em torno de uma agenda de mudanças baseadas nas idéias da Nova Gestão Pública. A ENAP teve papel decisivo neste esforço em função da fragilidade da comunidade acadêmica de administração pública e da desconfiança de muitas das existentes em relação ao conteúdo das propostas do governo.

No ciclo de reformas relacionadas com os PPAs 1996-1999 e 20002003, dois tipos de comunidade de especialistas atuaram de forma combinada: uma ligada ao setor privado e outra ligada ao setor público. A primeira era formada fundamentalmente por profissionais formados nas técnicas de qualidade total e gestão de projetos. A segunda era constituída pelos quadros da carreira de planejamento e orçamento e solidamente enraizada na burocracia estatal.

As reformas do primeiro ciclo começaram com grande ímpeto, alcançaram clímax rapidamente, quando a proposta foi enviada para o Congresso e foram gradativamente perdendo momentum. As reformas, no âmbito do Brasil em Ação e do Avança Brasil, foram incrementais, num crescendo, com alguns saltos de patamar ao longo do processo, porém sem retrocessos e praticamente à margem da arena política, salvo nas negociações orçamentárias anuais.

A busca do debate público aberto foi a tônica dos esforços desenvolvidos por Bresser Pereira e sua equipe no primeiro mandato, mas consensos foram mínimos e os esforços de persuasão na maior parte dos casos fracassou, em especial quanto a conquistar o apoio dos ministros da Presidência, da área econômica e de Cardoso para as principais teses das propostas. No ciclo de mudanças ligados aos dois PPAs em questão, o encaminhamento foi tecnocrático e hierárquico. Houve momentos de consultas e discussões, porém sempre controladas a partir do topo do processo. A necessidade de persuasão não era tão grande em função de a SPI dispor de mecanismos compulsórios - notadamente sistemas de informação, mais efetivos que legislações - para forçar a adesão das 
diversas áreas do governo às novas rotinas que foi introduzindo ao longo

do processo (mesmo que com sucesso discutível).

O primeiro ciclo de reformas teve a liderança de um único policy entrepreneur. Bresser Pereira foi formulador, negociador, campaigner e administrador. Teve o apoio de uma equipe solidária ao seu chefe, mas não a distância que o separava dos demais era visível. O segundo ciclo, teve na figura de José Silveira o personagem mais emblemático, porém a atuação do ministro Kandir, no primeiro mandato, e de seu diretor Ariel Pares, no segundo, tornaram seu papel menos solitário que no caso de Bresser Pereira.

Outra distinção importante também diz respeito à carreira de ambos. Bresser formou-se em Direito, mas fez carreira de economista, embora sempre tenha atuado em múltiplas áreas. Silveira fez uma carreira de engenheiro de uma estatal única - a Petrobras - movendo-se depois para outros desafios no setor público. Enquanto o primeiro tinha uma longa carreira pública como acadêmico, executivo, político e homem público, o segundo cumpriu uma trajetória mais discreta, porém mais focada nas instâncias de chefias intermediárias de empresas estatais e órgãos públicos.

O primeiro ciclo de reformas se encerrou com a extinção do MARE e com o deslocamento de Bresser Pereira para outra pasta, paradoxalmente poucos meses após a aprovação da reforma constitucional pela qual tanto lutara. Não se pode falar em implementação das reformas, porque as mesmas foram abandonadas na esfera federal ou modificadas para emergirem em outros contextos como no caso do PPA.

No caso das reformas introduzidas pelo Brasil em Ação e Avança Brasil, o ciclo se encerrou com eleição do Governo Lula. Embora a sistemática de elaboração do PPA tenha sido não apenas mantida como de certa forma, inclusive, enriquecida com a abertura do debate de sua elaboração à sociedade civil e a outros níveis de governo, os conceitos e princípios que nortearam sua evolução no governo anterior não foram efetivamente assimilados e sancionados pelo novo governo.

Ambos ciclos de reformas apresentaram resultados dignos de registro, embora não necessariamente nas áreas que priorizassem. Bresser Pereira obteve mais sucessos em sua agenda tradicional, não necessariamente associável à Nova Gestão Pública que nas inovações deste âmbito. Enfrentou problemas de natureza mais estrutural também. A revitalização dos concursos públicos no âmbito do chamado núcleo estratégico, o controle da folha de pagamentos, a produção de estatísticas sobre pessoal regularmente são exemplos de inequívoco sucesso de sua atuação. Já a implementação das agências executivas e das organizações sociais obteve resultados muito aquém dos esperados, bem como a disseminação de contratos de gestão entre a administração direta e os órgãos para estatais criados no processo. 
Já no caso do Brasil em Ação e do Avança Brasil, os resultados foram sendo progressivamente construídos e traduzidos em rotinas administrativas codificadas em sistemas de informação. Os resultados foram de certa forma institucionalizados, embora sem necessariamente serem bemsucedidos em função de se ter negligenciado aspectos organizacionais e humanos indispensáveis para o efetivo sucesso das inovações. Nem a figura dos gerentes, nem a chamada contratualização de resultados efetivamente funcionaram, embora a arquitetura para tal tenha sido moldada.

Finalmente, é importante ressaltar que em ambos os casos os reformistas ficaram concentrados em apenas um locus institucional - no caso do MARE - ou em basicamente um circuito - SPI, SOF e SPOAs - no caso do segundo. Neste sentido a conquista de apoios em outras áreas-chave do governo foi um desafio para ambos, embora as resistências sofridas por Bresser Pereira tenham se mostrado mais fortes e contundentes.

\section{Conclusão e perspectivas}

Quanto maior a frustração dos governantes com a lentidão dos resultados de suas ações, maior a sua propensão a adotar acriticamente soluções codificadas e de adoção aparentemente fácil. $\mathrm{O}$ apelo a soluções gerenciais é permanente no setor privado e espasmódico na esfera pública. Emula a heróica figura do dirigente comprometido com resultados e não com tergiversações. Contorna as complexidades e desgastes inerentes ao discurso político partidário. Ignora as nuances das discussões sobre políticas públicas e dos contraditórios que suscitam. Permite analogias instantâneas com empresas, seja de que porte elas forem, em linguagem familiar à grande parcela da sociedade que vive, produz e consome no contexto das relações de mercado.

O uso abusivo da retórica gerencial no período 1995-2002 gerou certo grau de saturação e estigma do termo, mas não das idéias que abrange por três razões. A primeira diz respeito ao seu uso cotidiano no mercado privado, com ou sem a adoção pelo setor público de conteúdos gerenciais. A segunda diz respeito ao grau de consolidação de alguns conceitos originalmente oriundos do gerencialismo como qualidade, customização, contratualização de resultados e outros, para além de divergências de natureza ideológica. A terceira diz respeito à própria natureza objetiva de alguns dos problemas enfrentados pelo governo - de natureza gerencial.

O que não está claro ainda, transcorrido o primeiro ano do Governo

Lula, é o diagnóstico do lugar das reformas gerenciais no contexto das 
políticas de gestão pública do governo. O gerencialismo pode trazer proposições instigantes para alguns dos problemas do governo, porém, com certeza, não para todos. No Ministério de Planejamento, Orçamento e Gestão, o documento Gestão Pública Para Todos (MPOG) ${ }^{8}$ traz importantes propostas de encaminhamento do tratamento de questões afetas à política de gestão pública, mas ainda não extrapolou a jurisdição da Secretaria em que foi gerada. Os estratégicos secretários de Patrimônio da União e de Recursos Humanos não chegaram a concluir seu primeiro ano de mandato, sendo substituídos por novos titulares ainda em 2003.

O legado controverso dos dois ciclos gerenciais dos últimos oito anos não foram ainda devidamente analisados, avaliados e destrinchados. Há um grande desconhecimento dos resultados das aplicações de propostas gerenciais à reestruturação do aparato do Estado e à vertebração do PPA. Na medida em que estas experiências são ainda pouco discutidas e qualificadas fica mais difícil aprofundar avanços, problema este agravado pela alternância do poder e pela ascensão de um novo grupo dirigente com relativamente pouca experiência da administração federal.

Os impasses da administração pública brasileira decorrem, em grande parte, da ausência de compreensão dos vetores transformadores que incidem simultaneamente sobre a mesma: meritocrático, gerencial, fiscal e corporativo (Gaetani, 2003). O destrinchamento de cada um propicia a compreensão dos limites e potencialidades de cada uma destas abordagens. Os abusos cometidos em nome do vetor gerencialista - em especial quando apresentado antagonicamente ao meritocrático - contribuíram para uma mistificação de suas capacidades transformadoras nos dois mandatos de Cardoso. Porém, há que se tomar cuidado para não desprezar suas contribuições em tempos em que há escassez de propostas, déficits de formulação e dificuldades não desprezíveis a serem superadas.

Todos os quatro vetores de alguma forma se contrapõem aos fenômenos mais comuns da administração pública brasileira: clientelismo e populismo. Ambos encontram-se ou em exercício - notadamente no nível municipal - ou em estado latente - como no governo federal. À medida que as reformas gerenciais não forem compreendidas no âmbito de suas possibilidades e limitações, o menu de alternativas de políticas e arranjos se estreita com prejuízo para os setores que mais poderiam se beneficiar das contribuições da Nova Gestão Pública: aqueles integrantes da área social. 
1 A reforma administrativa de 1967 não foi o único precedente de idéias gerenciais na condução dos assuntos relacionados com a administração pública brasileira. Os grupos executivos do Governo Kubitscheck são um exemplo de um procedimento pragmático ad hoc próximo destas idéias. O gerencialismo militar simbolizado pelo protagonismo das empresas estatais no regime autoritário é um outro caso importante. Finalmente, a experiência do Ministério Extraordinário da Desburocratização é um exemplo clássico das idéias esposadas pela escola "liberation management". Porém, a experiência de 1967 possui mais bases para comparabilidade com as de 1995 e 1999, razão pela qual foi selecionada para integrar o texto.

2 O projeto de reforma administrativa de 1953, por ocasião do retorno da volta ao poder, nunca chegou a ser votado, embora na mesma época tenha se conseguido aprovar o Estatuto do Funcionalismo Público. As conclusões das comissões Cosb (Comissão de Simplificação Burocrática) e (Comissão de Estudos Técnicos para a Reforma Administrativa) Cepra - já no governo Kubitscheck - tampouco foram implementadas, embora tenham contribuído para a familiarização de seus membros - notadamente Roberto Campos na última - com o problema.

3 Roberto Campos dispensa apresentações. Simões Lopes representava a visão tradicional histórica da administração pública baseada nos princípios da progressive public administration. Carlos Veloso era um representante da tradição administrativista do direito público, vindo a ser, mais tarde, ministro da justiça. Jorge Flores - co-fundador da Fundação Getúlio Vargas com Simões Lopes e recentemente seu presidente antes de vir a falecer - trazia uma visão empresarial. Hélio Beltrão já era conhecido como um executivo público inovador e bem-sucedido após suas sucessivas passagens pelo IAPI, Petrobras e Secretaria de Planejamento do Estado da Guanabara. Teixeira Dias era um especialista no assunto com passagens pelo Dasp, Petrobras, BNDE e Light.

4 O Governo Castelo Branco marca inflexão, no que se refere às áreas de planejamento e administração. Até então formalmente ambas estavam sob jurisdição do Dasp, mas a passagem de Roberto Campos pelo Ministério Extraordinário do Planejamento marcou definitivamente a consolidação do mesmo na configuração da estrutura administrativa do Estado brasileiro e o declínio da área de administração pública.

5 Curiosamente um embate semelhante, com alguns elementos comuns, voltaria a ocorrer trinta anos mais tarde entre Bresser Pereira e Clovis Carvalho, como se verá mais adiante no texto.

6 Para uma detalhada análise comparativa das reformas previdenciárias, tributária e administrativa, ver Melo (2002).

7 Um exemplo desta disputa foi a questão da criação das agências reguladoras, assunto avocado pela Casa Civil para sua coordenação, apesar da óbvia necessidade de um protagonismo maior por parte do MARE. Outro exemplo importante foi a decisão da cúpula do governo de remeter à questão da previdência pública, então profundamente vinculada com os debates sobre a reforma do Estado, exclusivamente ao Ministério da Previdência.

${ }^{8}$ Foge ao escopo deste texto a discussão do documento, mas trata-se de ponto de partida obrigatório para o debate atual sobre as possibilidades da política de gestão pública no Governo Lula. 


\section{Referências bibliográficas}

Aucoln, Peter. Administrative reform in public management. Paradigms, principles, paradoxes, and pendulums, Governance 3, p. 115-137, 1990.

Banco Mundial. O PPA 2000-2003. Brasília, Banco Mundial, 2002.

Gaetani, Francisco. As políticas de gestão pública no Governo Lula. Res Publica, № 3 Vol 1, 2003.

GAETANI, Francisco. The reform of the state apparatus: an ex-ant analysis. London, MSc dissertation at London School of Political Science, 1998.

Hood, Christopher. Economic policy reversal. Buckingham, Open University Press, 1994.

KANDIR, Antonio. O caminho do desenvolvimento. São Paulo, Atlas, 1998.

KInGDON, John. Agendas, alternatives, and public policies. 2d, New York, Harper Collins, 1995.

MARE. Plano Diretor da Reforma do Aparato do Estado, MARE, Brasília, 1995.

MARE.Caderno 1 -A Reforma do Estado dos Anos 90: Lógica e mecanismos de controle, Brasília, MARE, 1997.

Melo, Marcus. Reformas Constitucionais no Brasil, Rio de Janeiro, Revan, 2002.

MPOG. Gestão Pública para Todos, Brasília, MPOG, 2003.

PSDB. Mãos à obra. São Paulo, PSDB, 1994. 
Revista do

Serviço

Público

Ano 54

Número 4

Out-Dez 2003

Francisco

Gaetani é

mestre em

administração

pública e

políticas

públicas pela

London School

of Economics

and Political

Science,

Especialista em

Políticas

Públicas e

Gestão

Governamental, professor da

PUC-MG e

atualmente

Assessor do

Representante

Residente do

Programa das

Nações Unidas para o

Desenvolvimento no Brasil.

Contato:

francisco.gaetani @ undp.org.br

Abstract

\section{O recorrente apelo das reformas gerenciais: uma breve comparação \\ Francisco Gaetani}

Reformas de corte gerencial não são uma novidade no Brasil e estão condenadas a reaparecerem de forma recorrente, dado o incessante processo de renovação das teorias de administração no setor privado. Dado permanente apelo que detêm junto à área governamental, é natural que estejam continuamente sendo transplantadas para o setor público com maior ou menor sucesso, conforme um conjunto de circunstâncias e características. O trabalho busca fazer uma breve análise comparativa dos processos de transformações em determinadas políticas de gestão pública nos dois ciclos de reformas autodenominadas gerenciais ocorridas nos dois mandatos de Fernando Henrique Cardoso. O texto identifica contrastes em relação a aspectos do policy making process nos dois momentos, com ênfase para os momentos relacionados com a formação da agenda, especificação de propostas e processos decisórios. Na primeira parte são recuperadas algumas questões comuns a outro esforço de reforma - no caso a de 1967 - e na conclusão, são feitos alguns comentários relacionados com o legado de reformas de cunho gerencial no contexto do governo atual.

\section{El recurrente apelo de las reformas gerenciales: una breve comparación Francisco Gaetani}

Reformas de caracter gerencial no son una novedad en el Brasil y están condenadas a reaparecer recurrentemente por el incesante proceso de renovación de las teorías de administración en el sector privado. Por el gran apelo que estas teorías tienen en el area gubernamental, es natural que estén siendo frequentemente transplantadas al sector público, com mayor o menor éxito, de acuerdo a un conjunto de factores e características. Este trabajo pretende realizar un breve análisis comparativo de los procesos de transformación en determinadas políticas de gestión pública, en los dos ciclos de reformas, autotituladas gerenciales, que sucedieron durante los dos mandatos presidenciales de Fernando Henrique Cardoso. El texto identifica contrastes en relación a aspectos del proceso de toma de decisiones políticas (policy making process) en los dos momnetos, dando énfasis a los momentos relacionados con el establecimiento de la agenda, la especificación de propuestas y procesos decisorios. En la primera parte son recuperadas algunas questiones comúnes a outro esfuerzo de reforma - la de 1967 - y en la conclusión son elaborados algunos comentarios relacionados al legado de reformas de caracter gerencial en el contexto del gobierno actual.

\section{The recurring appeal of managerial reforms: a brief comparison Francisco Gaetani}

Reforms involving managerial cuts are not new in Brazil and are condemned to resurface recurrently as a result of the incessant renovation process of administrative theories in the private sector. In view of their permanent appeal to the government area, it is natural that they are continually being transplanted to the public sector with a greater or lesser degree of success depending on a number of circumstances and characteristics. The paper is intended to make a brief comparative analysis of transformation processes in certain public management policies in the two self-called managerial reform cycles occurred during the two terms that Fernando Henrique Cardoso served as president of Brazil. The paper 
identifies contrasts related to aspects of the policy making process at both moments, with an emphasis on the moments related to the formation of the agenda, specification of proposals and decision-making processes. The first part revives issues common to another reform effort - in this case the 1967 effort - and the conclusion presents comments about the legacy of managerial reforms in the present government context. 
